\title{
IMPLEMENTASI METHODE PDCA DALAM MENURUNKAN DEFECT SEPATU TYPE CAMPUS DI PT. PRIMA INTEREKSA INDASTRI (PIN)
}

\author{
Dedy Khaerudin'), Asep Rahmatullah' ${ }^{2)}$ \\ ${ }^{1,2}$ Fakultas Teknik, Universitas Bina Bangsa \\ email: dedy.khaerudin.binabangsa.ac.id
}

\begin{abstract}
PT. Prima Intereksa Industri perusahan yang bergerak dalam pembuatan alas kaki, dalam beberapa tahun terakhir mengalami penurunan produksi, terutama jenis sepatu type campus yang di akibatkan oleh cacat mencapai $45 \%$ dari target produksi. Metode PDCA (Plan-Do-Check-Action) merupakan salah satu cara yang dapat digunakan untuk meningkatkan kualitas produk. Dalam methode ini mampu menyelesaikan permasalahan secara radikal dan berkelanjutan yang sesuai dengan konsep lean improvment. Penelitian di lakukan diline 7 meliputi pengambilan data dari cutting, cementing, buffing, sewing, defect debu dari 231 sepatu menjadi 43 sepatu, Benang panjang dari 150 sepatu menjadi 10 sepatu, lem berlebih dari 102 sepatu menjadi 24 sepatu, Hot melt dari 57 sepatu menjadi 0 unit sepatu, target implementasi lean secara garis besar tercapai $90 \%$ untuk keseluruhan pada line 7.
\end{abstract}

Kata Kunci: Kualitas, Defact, 5 whay, PDCA, lean, Produktivitas.

Abstrak: PT. Prima Intereksa The company which is engaged in manufacturing footwear, has experienced a decline in production in the past few years, especially the type of campus type shoes caused by defects reaching $45 \%$ of the production target. The PDCA (Plan-Do-Check-Action) method is one way that can be used to improve product quality. In this method, it is able to solve problems radically and continuously in accordance with the concept of lean improvment. Research conducted in line 7 includes taking data from cutting, cementing, buffing, sewing, defect dust from 231 shoes to 43 shoes, thread length from 150 shoes to 10 shoes, excess glue from 102 shoes to 24 shoes, Hot melt from 57 shoes to 0 shoe units, the lean implementation target is generally $90 \%$ achieved for the whole on line 7

Keywords: Quality, Defact, 5 whay, PDCA, Lean, Productivity

\section{PENDAHULUAN}

Adidas merupakan perusahaan yang berdiri lebih dari 80 tahun, didirikan oleh seoarang berkebangsaan Jerman yaitu Adolf (Adi) Dassler, perusahaan ini mulai memproduksi sepatu pada 1920-an di Herzogenaurach dekat Nuremberg.

Adidas merupakan salah satu perusahaan yang bergerak dalam bidang manufaktur alas kaki yang akan terus berusaha untuk meningkatkan kualitas hasil produk perusahaanya dalam tiap lini produksi. Dimana selama ini salah satu penentu kualitas produk perusahaan yang di terapkan Adidas ialah dengan melihat kemampuan perusahaan mengefektifkan dan mengefisiesikankan produktivitas dalam menjalankan proses produksi secara tepat untuk meminimilasisai waste yang dihasilkan selama proses produksi perusahaan.
Untuk mencapai efektif dan efisien suatu kualitas produk yang maksimal Lean di terapkan dalam upaya menghilangkan waste dan meningkatkan value added produk dengan tujuan nilai rasio kepada pelanggan (customer value) meningkat terus-menerus secara maksimal.

Didalam waste terdapat aktivitas kerja yang tidak menciptakan nilai tambah dan tidak dapat dihindarkan karena berbagai alasan (type one waste), dan aktivitas kerja yang tidak menciptakan nilai tambah dan dapat dihilangkan segera (type two waste). Type two waste ini sering disebut sebagai waste.

Dr. W. Edwards Deming, yang melahirkan siklus Deming (Deming Cycle/Deming Wheel). Dimana kualitas dapat dikendalikan melalui proses terus-menerus dan berkesinambungan (Continuous Process Improvement). melalui penerapan PDCA (Plan-Do-Check-Action). Siklus ini digunakan untuk 
mengimplementasikan perbaikan kinerja proses produksi dalam sebuah perusahaan:

1. Plan merupakan aktivitas merencanakan, menetapkan standar kualitas dan mengembangkan secara spesifik pengendalian kualitas secara terus-menerus dan berkesinambungan.

2. Do merupakan aktivitas melaksanakan dan mengnendalikan rencana secara bertahap agar sasaran dapat tercapai.

3. Check merupakan aktivitas memeriksa, meneliti hasil yang dicapai dengan membandingkan standar yang telah ditetapkan agar pelaksanaannya sesuai jalur rencana yang telah di tetapkan.

4. Action merupakan aktivitas melakukan tindakan penyesuaian seperlunya hasil dari tahap check. Tindakan ini di bagi menjadi Corrective Action yang berupa solusi terhadap masalah yang dihadapi dan Standardization Action merupakan cara yang distandarisasi.

Siklus Deming yang telah dilakukan akan menghasilkan standarisasi kualitas produk yang akan ditetapkan secara keseluruhan dalam perusahaan dimana pola tersebut akan terus dilakukan untuk melakukan peningkatan proses selanjutnya sehingga terjadi siklus peningkatan proses yang terus menerus.

\section{METODE PENELITIAN}

Merupakan cara dan tahapan dalam pengumpulan dan pengolahan data, dimana dalam penelitian yang dilakukan di PT. Prima Intereksa Indastri (PIN) ini melalui pengambilan data kualitatif yaitu observasi, dokumentasi, wawancara (Field Research) dan data kuantitatif dengan mengambil jumlah cacat produk terhadap jumlah produksi. Data tersebut di analisis dan dilakukan perbaikan dengan menggunakan methode PDCA, kemudian hasilnya dapat di gambarkan dalam diagram Pareto

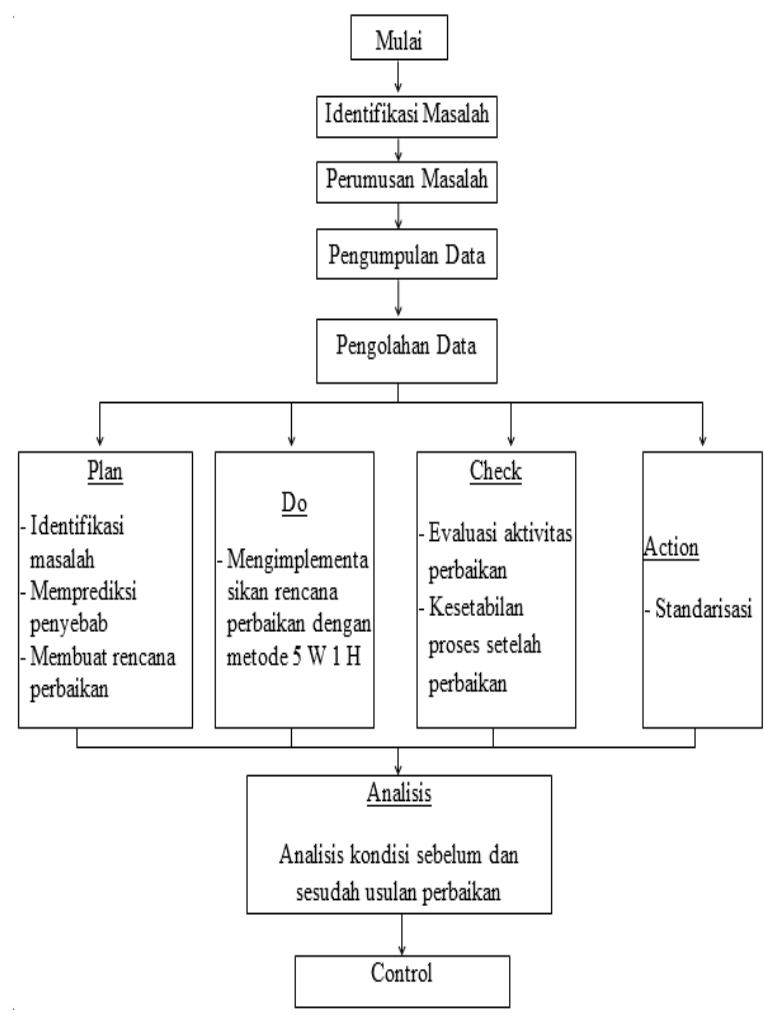

Gambar 1. Pengolahan Data.

\section{HASIL DAN PEMBAHASAN}

Ringakasan aktivitas yaitu melihat keseluruhan perusahan mencakup pengecekan seluruh kualitas produksi, dianalisa secara singkat untuk menentukan diarea/line mana yang akan difokuskan untuk dijidakan project penelitian, setelah itu di bentuk formasi team dan diberikan pengarahan mengenai peramsalahan dan langkah yang akan dirancang keseluruhan untuk mengatasi permasalahan tersebut.

Team focus dalam project line 1 yang akan dijadikan tolak ukur percontohan, setelah observasi team memperoleh keakuratan situasi data defect pada line 1 sebagai berikut:

Tabel 1. Data defect sebelum perbaikan line 7

\begin{tabular}{lc}
\hline Jenis Cacat & (Unitsepatu) \\
\hline Debu & 231 \\
Benang panjang & 150 \\
Lem berlebih & 102 \\
Hotmelt & 57 \\
& 540 \\
Total defect & 650 \\
Total Inspected & \\
\hline
\end{tabular}




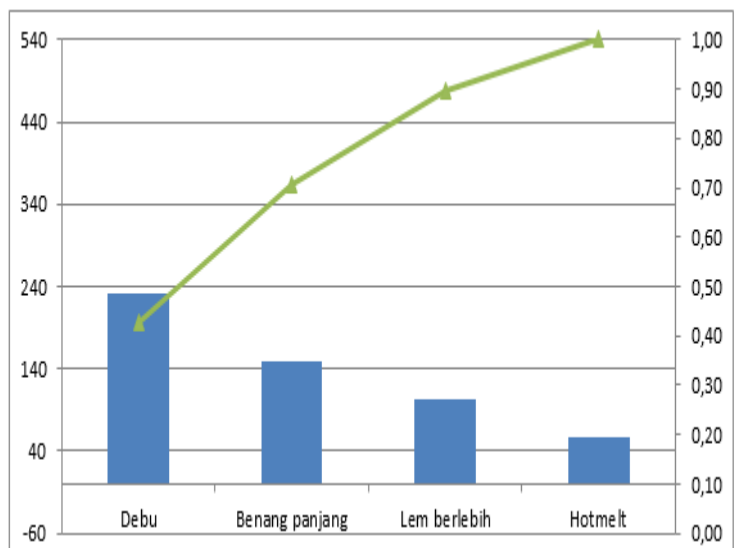

Gambar 2. Jumlah Cacat pada line 7

Analisa root cause

Analisa root cause dilakukan untuk memperoleh dan mengetahui akar masalah dimana masalah tersebut itu ada, muncul dan apa penyebabnya baik dari metode, aktivitas proses produksi, alat yang dipakai dalam produksi, operator yang bekerja, bahan yang digunakan, dengan analisa ini diinginkan untuk mengetahui seberapa besar masalah tersebut berpengaruh terhadap kegiatan operasional perusahaan.

\section{Implementasi methode PDCA}

Debu yang melekat di upper di akibatkan sebagian besar operator tidak melakukan pembersihan, air cleaning tidak bersih dan pekerjaan yang di lakukan seharusnya di dalam bok akan tetapi operator melakukan di luar bok disebabkan kaca buffing sehingga operator mengalami gangguan dalam melihat marking pada bagian upper sepatu

Point of cause: buffing operation

Direct cause: debu di upper

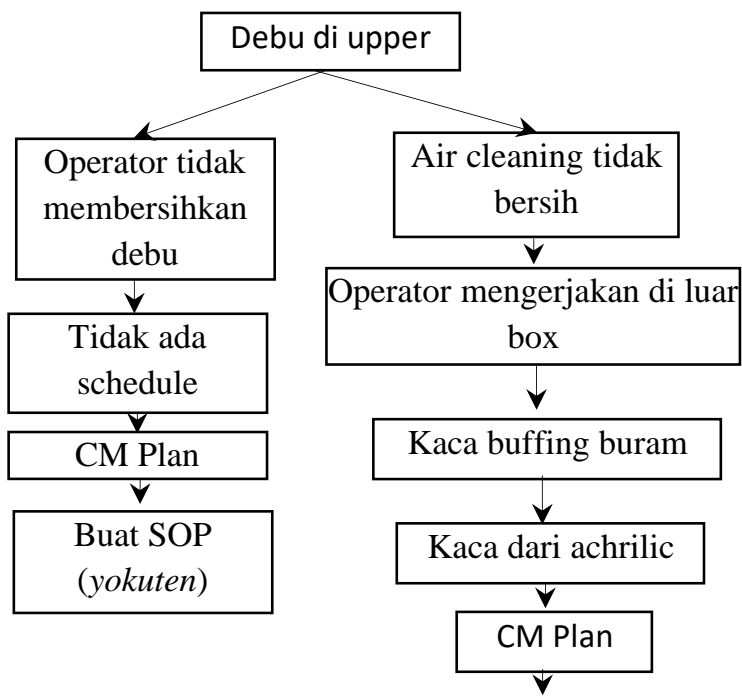

Ganti achrilic dengan

kaca

Gambar 3 CM plan debu pada upper
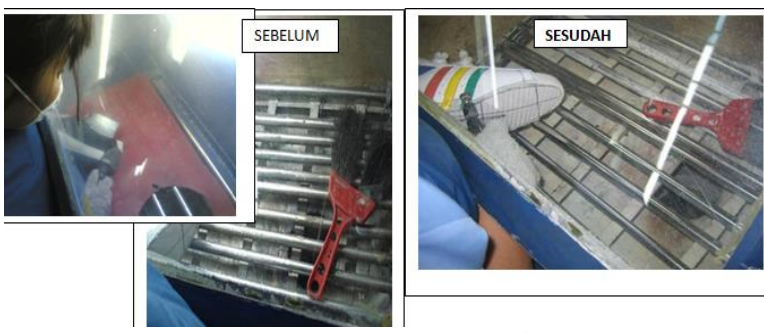

Gambar 4. Kondisi Sebelum dan Sesudah pada Upper

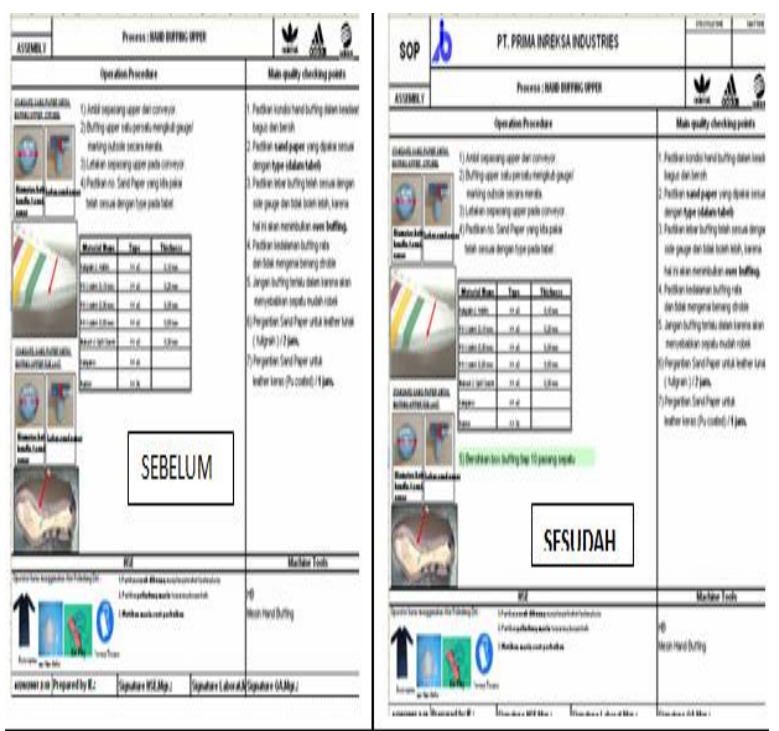

Gambar 5. SOP sebelum dan sesudah perbaikan

Point of cause: buffing bawah sepatu

Direct cause : banyak debu di area operasi

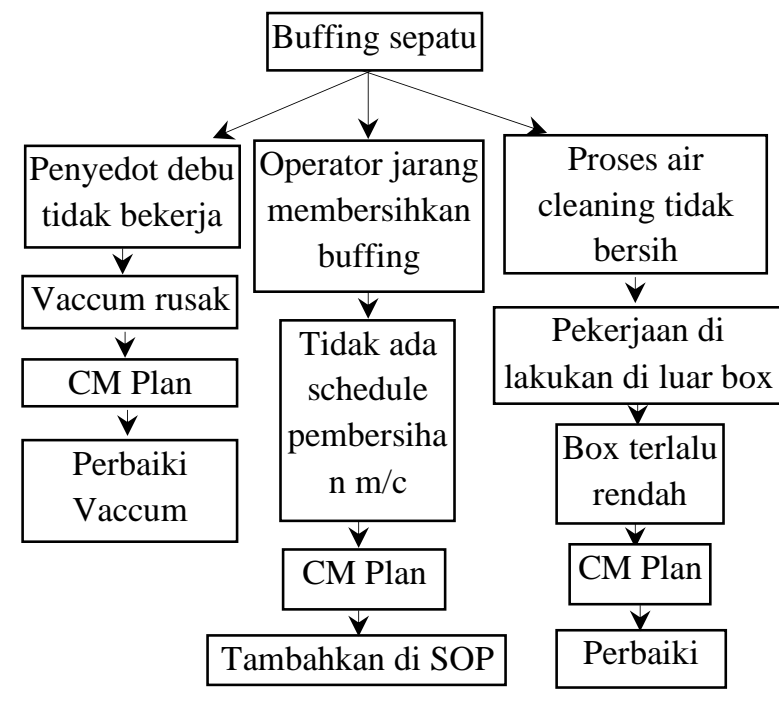

Gambar 6. CM Plan Buffing bawah sepatu 


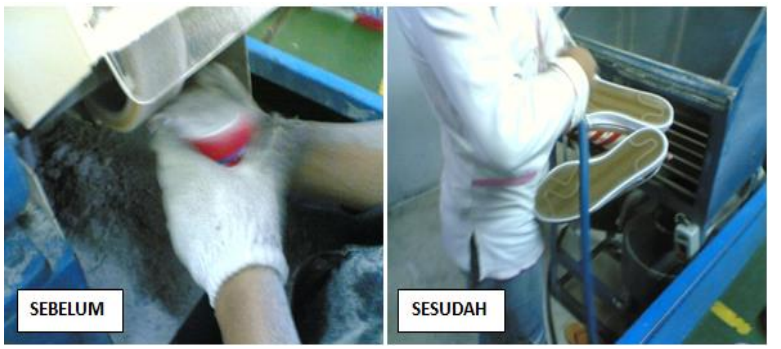

Gambar 7. Buffing bawah sepatu

Point of cause : Cutting operation

Direct cause : banyak debu di Cutting Board

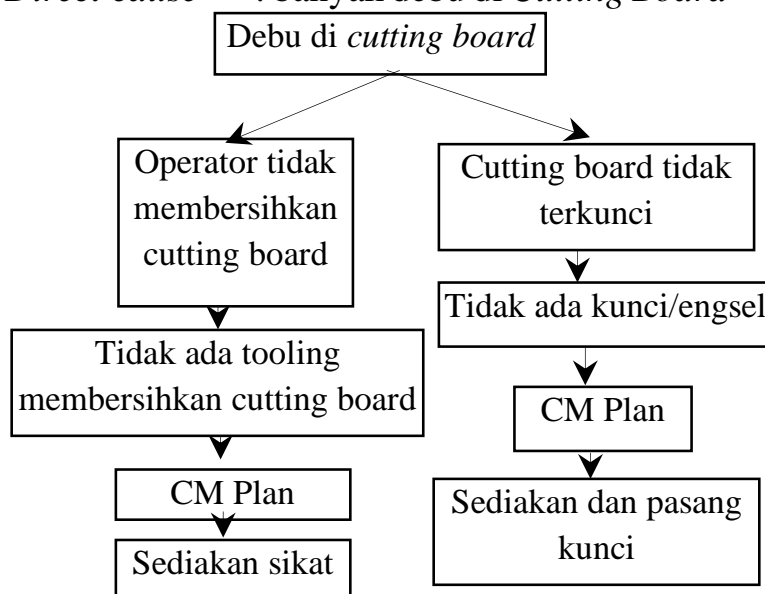
semir

Gambar 8. CM Plan Catting Operation

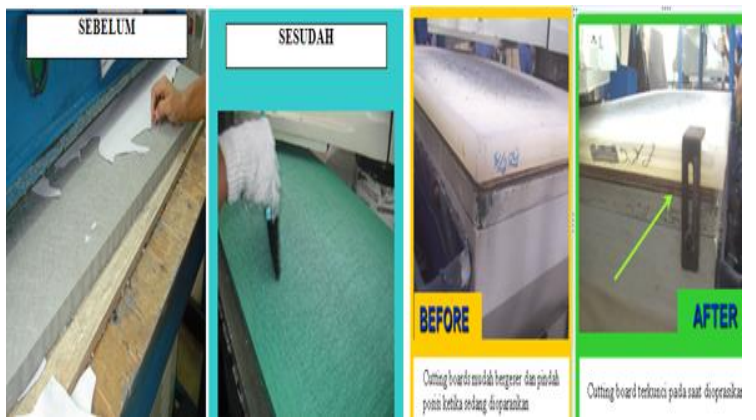

Gambar 9. Cutting Board sebelum dan sesudah perbaikan

Benang panjang di bagian upper di akibatkan tidak ada tindakan perlakuan untuk memotong sisa benang yang masih berada pada bagian upper hasil dari proses penjahitan di bagian sewing, rencana tindakan yang akan dilakukan dengan menyediakan gunting kecil dan membuat key poin di kanban agar operator melakukan proses pekerjaan dengan benar.

Point of cause : Sewing operation

Direct cause : benang muncul/ panjan

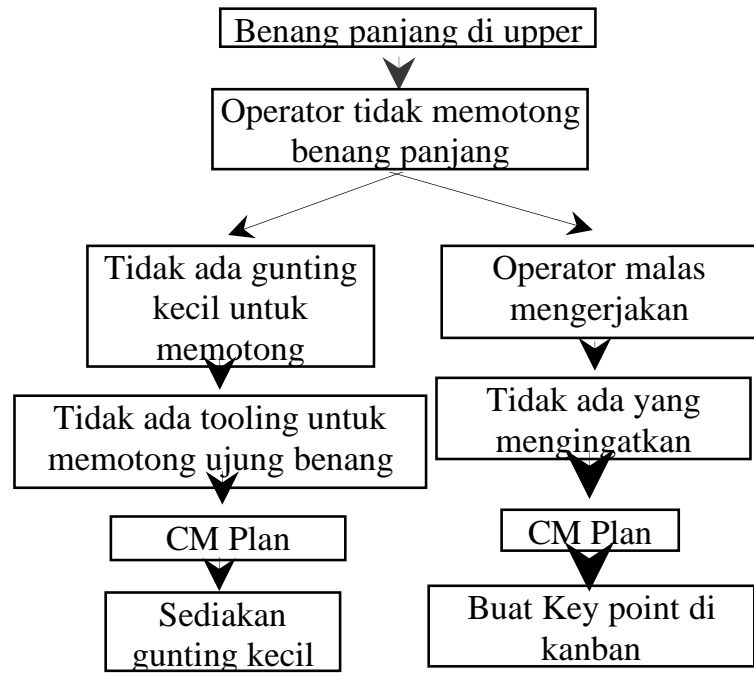

Gambar 10. CM Plan benang panjang pada upper

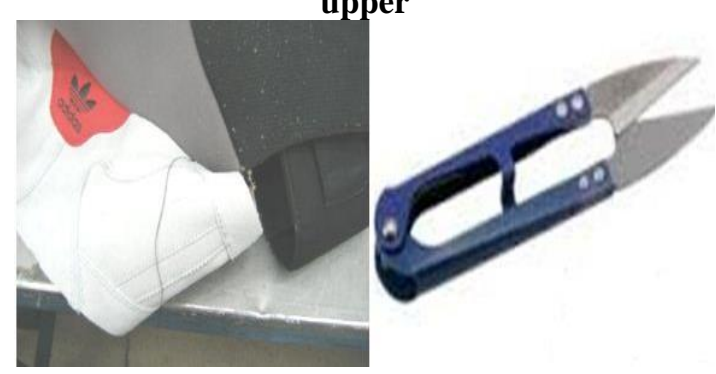

Gambar 11. Benang panjang pada upper

Lem berlebih pada daerah upper yang di akibatkan cairan primer langsung terkena garis batas, yang disebabkan operator langsung meletakan sikat kebagian atas garis.

Point of cause : primer upper

Direct cause : over primer

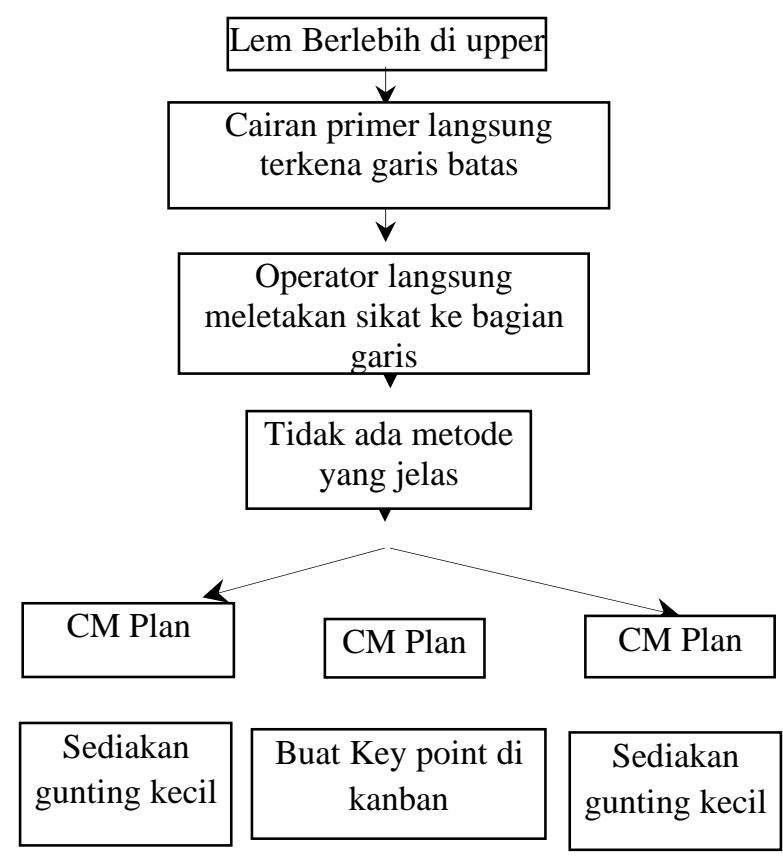

Gambar 12. CM plan lem berlebih pada upper 


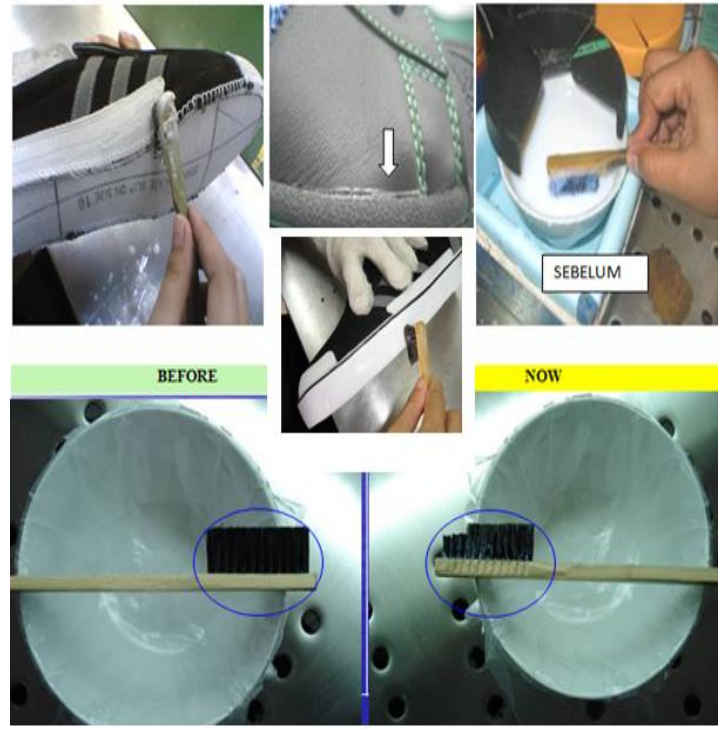

Gambar 13. Modifikasi kuas

Point of cause : cement pada foxing Direct cause : kelebihan cement pada foxing Kelebihan cement pada foxing

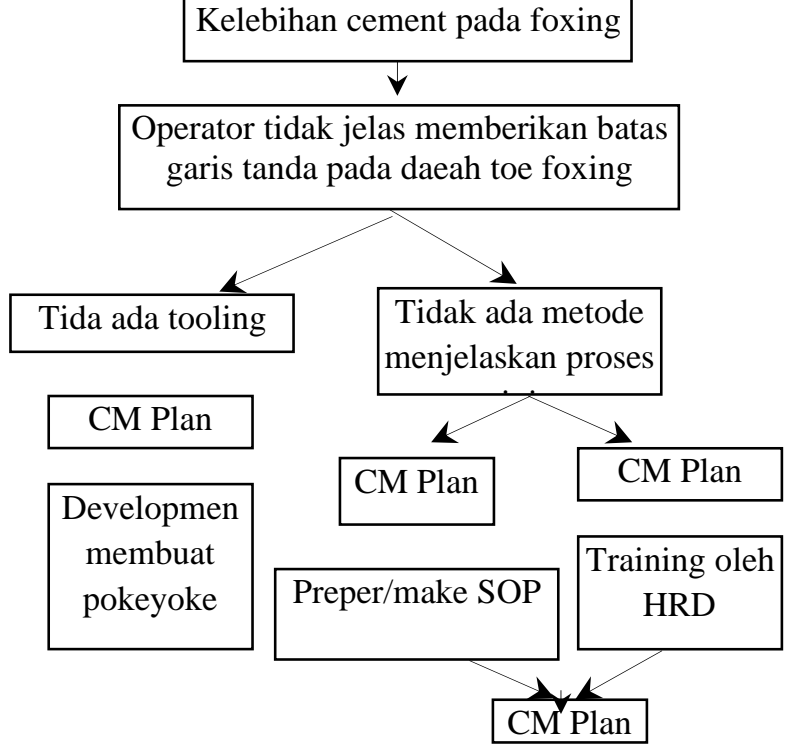

Meeting dengan kepala regu

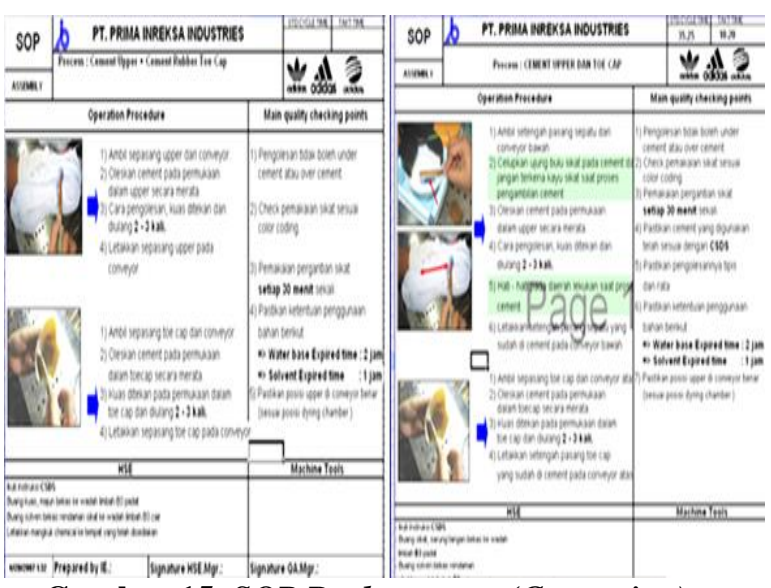

Gambar 15. SOP Replacement (Cementing)

Pada gambar 14 menjelaskan bahwa Kelebihan cement pada foxing diakibatkan oleh ketidak jelasan operator dalam memberikan batas garis pada daerah toefoxing hal tersebut dikarnakan tidak ada metode dan toolling sebagai petunjuk dalam melakukan pekerjaan yang harus di lakukan oleh operator. Untuk mengatasi masalah tersebut harus dilakukan pembuatan SOP, pokeyoke dan adanya tarining yang di lakukan oleh HRD.

Pada Gambar 15 menunjukan hasil perubahan sebelum dan sesudah dilakukan improvisasi dengan pembuatan setandar oprasional pekerjaan mengalami penurunan jumlah cacat hingga mencapai $76 \%$ dari 102 sepatu menjadi 24 unit sepatu.

Poin masalah yang terjadi di proses hot melt masih berada di upper, operator meletakan insole di area conveyor, pemasangan insole tidak tepat dan lebih lama pada bagian outsole hal tersebut yang mengakibatkan hot melt mengering.

Point of cause : Hot melt process

Direct cause : Hot melt masih berada di upper

Gambar 14. CM plan cementing pada Foxing 


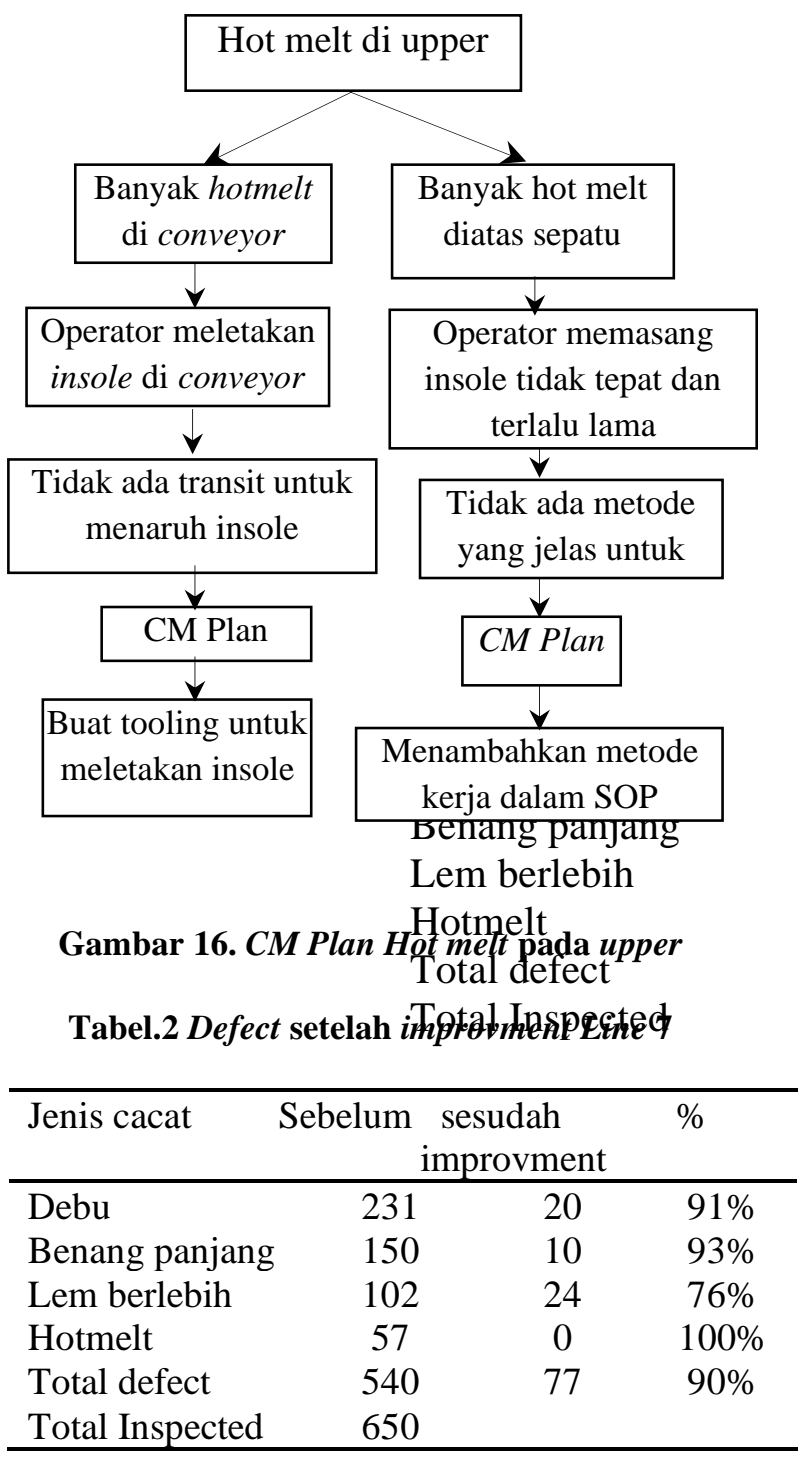

Pada gambar 16 menujukan rencana perbaikan yang pada dilakukan pada upper yang diakibatkan oleh hot melt dengan rencana pembuatan tooling untuk meletakan insole dan menambahkan metode kerja pada SOP yang seharusnya operator lakukan dalam pekerjaan.

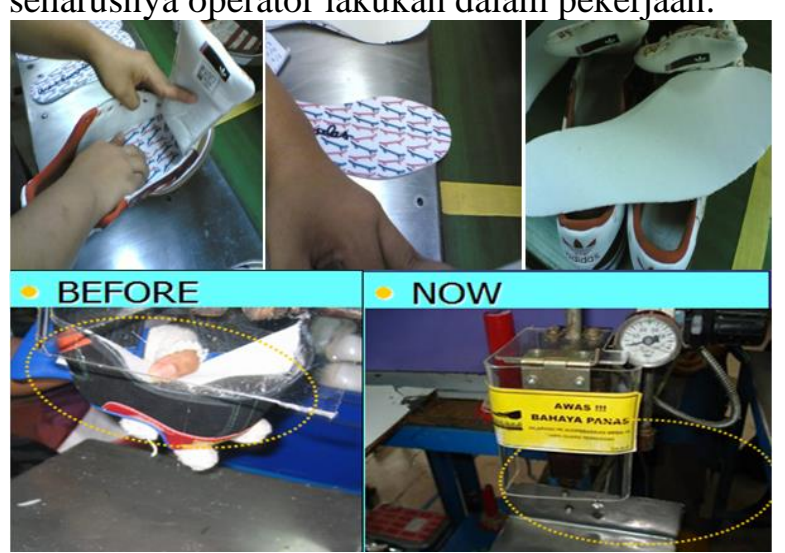

Gambar 17. Proses sebelum dan sesudah hot melt pada upper
Gambar 17 menunjukan proses perubahan yang dihasilkan setelah melakukan dan melaksanakan rencan perbaikan seperti yang tertera pada gambar 16 hasilnya menujukan perubahan yang sangat siginifikan $100 \%$, dari kondisi 57 sepatu menjadi 0 unit sepatu.

\section{KESIMPULAN}

PT. Prima intereksa indastri (PIN) menerapkan sistem make to order dalam merencanakan proses produksinya sesuai dengan permintaan konsumen, oleh karena itu kualitas produk sepatu yang dihasilkan haruslah memiliki standar kualitas yang sangat baik Lineuk (unissegatkepuasan dari konsumen.

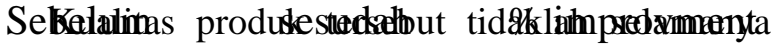
berfjalan sesuai deggan keinginan gponsumen, \$igoana dalam poses produksig3perjalan megnemukan kecacatan output predu标 yang djhasilkan. Pada o tahun 2019 ${ }_{105 \%}$ Prima intereksa indastri (PJN) dimana terlibat output yang dihasilkan per bulannya masih dibawah rencana atau target produksi yang diinginkan, permasalah tersebut setelah diteliti ternyata faktor yang dominan mempengaruhi output perusahan adalah dikarnakan defect.

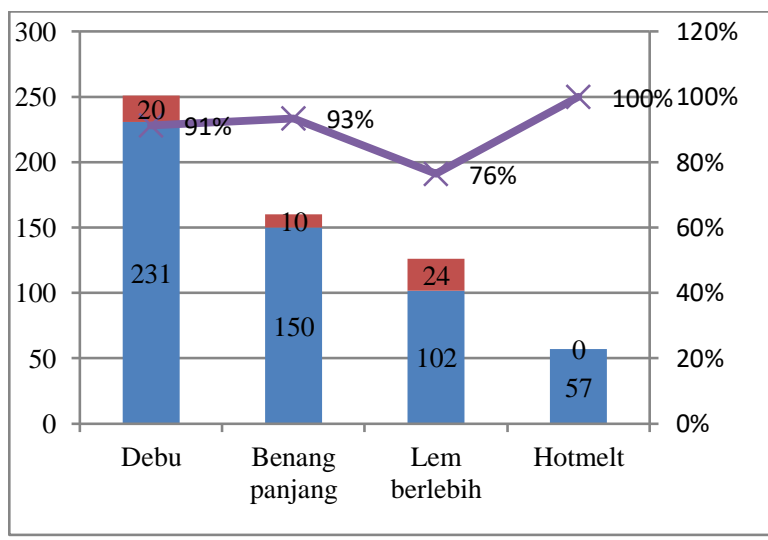

Gambar 18. Jumlah Cacat Sebelum dan Sesudah Improv pada line 7

Dimana defect sebelum diimplementasikanya lean manufactur yaitu Total defect secara keseluruhan di line 7 meliputi pengambilan data dari cutting, cementing buffing, sewing, defect debu dari 231 menjadi 43, Benang panjang dari 150 menjadi 10, Lem berlebih dari 102 menjadi 24, Hot melt dari 57 menjadi 0 unit sepatu. 


\section{DAFTAR PUSTAKA}

Martono, R.V "Analisis Produktivitas dan Efisiensi". Jakarta: PT. Gramedia Pustaka Utama, 2019.

Ross, E and Holland, A "100 Great Business Ideas" Jakarta: PT. Mizan Publika, 2007.

Normindhawati, L and Enterprise, J "Thinking Gelobal" Jakarta: PT. Elex Media Komputindo, 2014.

V. Gaspersz, Lean Six sigma for Manufacturing and Service Industries. Jakarta: PT Gramedia Pustaka Utama, 2011.

M. N. Nasution, Manajemen Mutu Terpadu (Total Quality Manajement) Edisi kedua. Bogor: Penerbit Galia Indonesia 2005

Jeffrey, K. Liker and David Meier "The Toyota Way Fieldbook". Jakarta: PT.Gelora Aksara Pratama, 2006.

B. Jovanović, J. Filipović, and V. Bakić "Energy management system implementation in Serbian manufacturing Plan-Do-Check-Act cycle approach" in Journal of Cleaner Production, 2017, Vol. 162, PP: 1144-1156

E. Gidey, K. Jilcha, B. Beshah and D. Kitaw "The Plan-Do-Check-Act Cycle of Value Addition", in Industrial Engineering \& Management Vol.3, Issue 1, 3: 124. doi: 10.4172/2169-0316.1000124

Dr. A.Chakraborty "Importance of PDCA Cycle for SMEs" in SSRG International Journal of Mechanical Engineering ( SSRG-IJME ), 2016, Vol. 3 Issue 5. doi: www.internationaljournalssrg.org

A.R. Vargas, K.C Arredondo-Soto , T.C. Gutiérrez and G.Ravelo "Applying the Plan-Do-Check-Act (PDCA) Cycle to Reduce the Defects in the Manufacturing Industry. A Case Study" in Applied Sciences-Open Access Journal, Vol. 8, PP: 2181 2018, doi:10.3390/app8112181

E. Lodgaard and K.E. Aasland "An Examination Of The Application Of PlanDo-Check-Act Cycle In Product Development" In International
Conference On Engineering Design, ICED11, 2011

ZHAO Pu "The Model of Plan Do Check and Act" to Improve Chinese EFL Learners' Writing Strategies" in CS Canada Higher Education of Social Scienc, 2014, Vol.7, No.1, pp.107-112, ISSN 1927-0240, Doi: $10.3968 / 5280$

P.M, Patel and V.A Deshpande "Application Of Plan-Do-Check-Act Cycle For Quality And Productivity Improvement-A Review" In 2017 International Journal for Research in Applied Science \& Engineering Technology (IJRASET), Vol.5, Issue I, ISSN: 2321-9653

R. Maruta "Maximizing Knowledge Work Productivity: A Time Constrained and Activity Visualized PDCA Cycle" In 2012 Journal Corporate Transformation, Vol.19, Issue 4, PP: 203-214 doi.org/10.1002/kpm.1396

M.J, Kocik, "PDCA cycle as a part of continuous improvement in the production company-a case study" In 2017 Production Engineering Archives, Vol.14, PP:19-22, ISSN 2353-7779

S. Santoso and D. Mayrifka, "Analysis Problem and Improvement of Appearance Aesthetics Product Model HC C5 / XT with Method of Plan-Do-Check-Action (PDCA) In Pt. XXXX”, In 2019 International Journal of Innovative Science and Research Technology, Vol. 4, Issue 11, ISSN No:-2456-2165

Hassan, M. K "Applying lean six sigma for waste reduction in a manufacturing environment". In 2013 American Journal of Industrial Engineering, Vol.1(2), pp: 28-35, Doi: 10.12691/ajie-1-2-4 